\title{
HUBUNGAN KUALITAS ANTE NATAL CARE DENGAN PRAKTIK MENYUSUI YANG BENAR PADA IBU NIFAS DI RUANG WIJAYAKUSUMA RSUD SERANG TAHUN 2012
}

\begin{abstract}
Ahmad* $^{*}$
ABSTRAK

Praktek menyusui yang baik dan benar perlu dipelajari oleh setiap ibu karena menyusui itu sendiri bukan suatu hal yang reflektif atau instingtif saja, tetapi merupakan suatu proses. Proses belajar yang baik khususnya bagi ibu yang pertama kali melahirkan karena biasanya ibu melahirkan anak pertama tidak memiliki ketrampilan menyusui yang benar. Dengan demikian ibu perlu belajar berinteraksi dengan "manusia baru" ini agar dapat sukses dalam memberikan yang terbaik bagi bayinya. Penelitian ini bertujuan untuk memperoleh informasi tentang hubungan Kualitas Ante natal care dengan praktik menyusui yang benar di Ruang Wijayakusuma RSUD Serang tahun 2012. Desain penelitian ini adalah Cross Sectional. Populasi penelitian adalah semua ibu nifas yang dirawat di ruang Wijayakusuma RSUD Serang, dengan jumlah sampel sebanyak $177 \mathrm{ibu}$ nifas diambil dengan cara asidental sampling. Pengumpulan data dilakukan melalui kuesioner. Hasil penelitian menunjukkan bahwa lebih dari setengahnya ( 55,9 \% ) responden kurang baik dalam melakukan praktik menyusui. Hasil penelitian juga menunjukkan bahwa kualitas ANC saat hamil, paritas ibu serta pengetahuan ibu tentang menyusui berhubungan dengan praktik menyusui yang benar. Sementara itu pendidikan ibu tidak berhubungan dengan praktik menyusui yang benar.Kualitas ante natal care dan paritas berhubungan dengan praktik menyusui yang benar. Ibu nifas dengan kualitas ante natal care yang kurang baik, memiliki peluang 5,389 kali untuk melakukan praktik menyusui yang kurang baik dibandingkan ibu nifas dengan kualitas ante natal care yang baik Perlunya petugas kesehatan untuk selalu memberikan penyuluhan tentang praktik menyusui yang benar pada setiap ibu hamil yang melakukan layanan ante natal maupun upaya promosi lainya seperti leaflet atau brosur yang dapat dipelajari ibu hamil.
\end{abstract}

Kata Kunci: Antenatal Care, Praktik Menyusui

*Poltekkes Kemenkes Banten 


\section{Pendahuluan}

Pemberian ASI yang baik adalah sesuai kebutuhan bayi istilahnya on demand, kalau ASI diberikan pada saat anak sudah menangis sebenarnya itu sudah terlambat. Keberhasilan menyusui harus diawali dengan kepekaan terhadap waktu yang tepat saat pemberian ASI. Kalau diperhatikan sebelum sampai menangis bayi sudah bisa memberikan tanda-tanda kebutuhan akan ASI berupa gerakangerakan memainkan mulut dan lidah atau tangan di mulut. Ketepatan waktu saja tidak cukup, tak jarang kegagalan dalam menyusui terjadi. Kegagalan biasanya disebabkan karena teknik dan posisi yang kurang tepat bukan karena produksi ASInya yang sedikit. Kegagalan teknik menyusui bisa terjadi karena bayi yang bersangkutan pernah menggunakan dot

Sekitar 40 tahun silam, jumlah wanita yang memilih menyusui sendiri bayinya mulai berkurang. Jumlah terendah terjadi di tahun-tahun awal 70an ketika kurang dari $40 \%$ yang memilih ASI, dan pada minggu ke enam setelah melahirkan kurang dari $20 \%$ memberikan ASI kepada bayinya. Alasan ketidak suksesan memberi ASI telah dipelajari, salah satu faktor dikarenakan fungsi payudara di masa sekarang ini sebagai simbolis seksual, bahwa payudara adalah zona terlarang dan harus disembunyikan dan tidak boleh diekspos. Selain faktor di atas masalah yang muncul seperti; puting susu yang terlipat ke dalam, puting susu lecet, dan lain-lain. Ironisnya ahli laktasi menemukan banyak wanita mengalami masalah dalam teknik menyusui (Lee, 2006 ).

Praktek cara menyusui yang baik dan benar perlu dipelajari oleh setiap ibu karena menyusui itu sendiri bukan suatu hal yang reflektif atau instingtif saja, tetapi merupakan suatu proses. Proses belajar yang baik bukan hanya untuk ibu yang pertama kali melahirkan karena biasanya ibu melahirkan anak I tidak memiliki ketrampilan menyusui yang benar. Dengan demikian ibu perlu belajar berinteraksi dengan "manusia baru" ini agar dapat sukses dalam memberikan yang terbaik bagi bayinya (Mellyana, 2003 ).

Berdasarkan Hasil wawancara saat melakukan studi pendahuluan penelitian tentang teknik menyusui yang benar pada 10 ibu nifas yang ada di Ruang Wijaya Kusuma RSUD Serang diperoleh hamper setengahnya (40\%) ibu tidak mengetahui teknik menyusui yang benar. Dari $10 \mathrm{ibu}$ nifas yang ada, diketahui 3 orang ibu diantaranya mengalami masalah dalam 
menyusui yakni puting susu lecet 2 orang dan payudara bengkak 1 orang. Dengan adanya masalah seperti puting susu lecet dan payudara bengkak membuat Ibu merasa tidak nyaman dalam memberikan ASI kepada Bayinya.

Tujuan untuk mengetahui hubungan kualitas ante natal care (ANC) dengan praktik menyusui yang benar di Ruang Wijaya Kusuma RSUD Serang tahun 2012 setelah dikontrol variable paritas, pendidikan pengetahuan

\section{Metode Penelitian}

Populasi penelitian ini adalah seluruh ibu nifas di Ruang Wijaya Kusuma RSUD Serang dengan rata - rata ibu nifas setiap bulannya sebanyak 316 orang Berdasarkan perhitungan perhitangan sampel pada penelitian ini, maka jumlah sampel yang diikutsertakan dalam penelitian ini sejumlah 177 responden. Pengambilan sampel dilakukan menggunakan Non Random Sampling yaitu pengambilan sampel secara Accidental Sampling yaitu pengambilan sampel pada responden / ibu nifas yang kebetulan ada pada saat pengumpulan data di ruang Wijayakusuma RSUD Serang. Pengumpulan data dilakukan dengan metode wawancara pada ibu nifas yang ada di ruang Wijayakusuma
RSUD Serang dengan menggunakan kuesioner yang telah disusun sebelumnya. Sementara untuk pengumpulan data tentang praktik menyusui yang benar dilakukan dengan metode observasi yang dilakukan oleh bidan yang bertugas di ruang Wijayakusuma RSUD Serang yang telah diberikan penjelasan sebelum melakukan pengamatan pada ibu nifas saat menyusui. Setiap responden dilakukan tiga kali pengamatan praktik menyusui. Setelah data dikumpulkan dan diolah, langkah selanjutnya yaitu melakukan analisis data. Analisa data dibagi menjadi tiga mcam yaitu analisa univariate, analisa bevariate, dan analisa multivariate .

\section{Hasil dan Pembahasan}

Hasil penelitian menunjukan bahwa lebih dari setengahnya $(55,9 \%)$, responden tidak melakukan praktik menyusui yang benar. masih ditemukan sebagian kecil responden ( 28,8 \%) memiliki kualitas ante natal care yang kurang baik. sebagian besar responden $(66,1 \%)$ termasuk multipara. Lebih dari setengahnya ( 58,2 $\%$ ) responden berpendidikan rendah.

Serta hampir setengahnya ( 44,6\%) responden memiliki pengetahuan kurang baik tentang praktik menyusui Hasil penelitian juga menunjukan bahwa 
responden yang melakukan praktik pendidikan tinggi ( 51,4 \% ). Hasil uji menyusui kurang baik proporsinya lebih statistic menunjukan bahwa tidak ada tinggai pada ibu dengan kualitas ANC hubungan antara pendidikan dengan praktik yang tidak baik $(80,4 \%)$ dibanding ibu menyusui yang benar.

dengan kualitas ANC yang baik ( $46 \%$ ). Responden yang melakukan praktik

Hasil uji statistic kai skuer pada alpha 0,05 diperoleh nilai $\mathrm{p}=0,00(\mathrm{P}<0,05)$, yang berarti bahwa secara statistic ada hubungan antara kualitas ANC dengan praktik menyusui yang benar. Hasil analisis lebih lanjut diperoleh nilai OR = 1,7 yang berarti bahwa ibu dengan kualitas ANC yang tidak baik memiliki peluang untuk melakukan praktik menyusui yang kurang baik 1,7 kali dibanding ibu dengan kualitas ANC yang baik.

Hasil uji statistic kai skuer pada alpha 0,05 diperoleh nilai $\mathrm{p}=0,01(\mathrm{P}<0,05)$, yang berarti bahwa secara statistic ada hubungan antara paritas dengan praktik menyusui yang benar. Hasil analisis lebih lanjut diperoleh nilai OR $=1,7$ yang berarti bahwa ibu dengan prmipara memiliki peluang untuk melakukan praktik menyusui yang kurang baik 1,43 kali dibanding ibu dengan multipara.

Responden yang melakukan praktik menyusui kurang baik proporsinya sedikit lebih tinggi pada ibu dengan pendidikan rendah (59,2\%) dibanding ibu dengan

lebih tinggi pada ibu dengan pendidikan rendah $(59,2 \%)$ dibanding ibu dengan pendidikan tinggi ( $51,4 \%)$. Hasil uji statistic menunjukan bahwa tidak ada hubungan antara pendidikan dengan praktik menyusui yang benar.

Responden yang melakukan praktik menyusui kurang baik proporsinya lebih tinggai pada ibu dengan pengetahuan kurang tentang praktik menyusui $(75,9 \%)$ dibanding ibu dengan pengetahuan yang baik $(38,8 \%)$.

Hasil uji statistic menunjukanc ada hubungan antara pengetahuan dengan praktik menyusui yang benar. Hasil analisis lebih lanjut diperoleh nilai $\mathrm{OR}=1,9$ yang berarti bahwa ibu dengan pengetahuan kurang tentang praktik menyusui memiliki peluang untuk melakukan praktik menyusui yang kurang baik 1,9 kali dibanding ibu dengan kualitas ANC yang baik.

Dari keseluruhan proses analisis yang telah dilakukan dapat disimpulkan bahwa variable independen ( kualitas ANC, pengetahuan, paritas dan pendidikan ) yang 
diduga berhubungan dengan praktik menyusui yang benar pada ibu nifas, ternyata hanya variable kualitas ANC, dan paritas yang secara significan berhubungan dengan praktik menyusui yang benar pada ibu nifas di ruang Wijayakusuma RSUD Serang.

Ibu dengan kualitas ante natal care yang kurang baik, memiliki peluang 5,389 kali untuk melakukan praktik menyusui yang tidak baik dibandingkan ibu dengan kualitas ante natal care yang baik, setelah dikontrol variable paritas. Dari kedua variable yang secara significan berhubungan dengan praktik menyusui yang benar, ternyata variable kualitas ante natal care merupakan variable yang paling dominan berhubungan dengan praktik menyusui yang benar.

Dari hasil analisis juga terlihat bahwa besarnya risiko kualitas ante natal care terhadap praktik menyusui yang benar semakin meningkat setelah dikontrol variable covariat, nilai prevalens rationya menajdi 5,389 (CI ; 2,200-12,184 ). Dengan demikian risiko sebenarnya dari pengaruh kualitas ante natal care yang tidak baik terhadap praktik menyusui yang benar adalah 5,389 kali dibanding kualitas ante natal care yang baik.
Praktek cara menyusui yang baik dan benar perlu dipelajari oleh setiap ibu karena menyusui itu sendiri bukan suatu hal yang reflektif atau instingtif, tetapi merupakan suatu proses. Proses belajar yang baik bukan hanya untuk ibu yang pertama kali melahirkan karena biasanya ibu melahirkan anak I tidak memiliki ketrampilan menyusui yang benar. Dengan demikian ibu perlu belajar berinteraksi dengan "manusia baru" ini agar dapat sukses dalam memberikan yang terbaik bagi bayinya (Mellyana, 2003 ).

Hasil penelitian menunjukkan bahwa lebih dari setengahnya ( $55,9 \%$ ) responden kurang baik dalam melakukan praktik menyusui. Gambaran ini menunjukan bahwa, masih cukup banyak ibu - ibu di masyarakat yang belum mampu melakukan praktik menyusui yang benar. Praktik menyusui sebenarnya merupakan perilaku pemberian Air Susu Ibu yang dilakukan ibu pada bayinya. Terbentuknya perilaku pada seseorang dipengaruhi oleh berbagai factor. L. Green menjelaskan perilaku seseorang akan muncul karena factor predisposing, enabling dan reinforcing. Pada hasil penelitian diketahui bahwa hampir setengahnya $(44,6 \%)$ responden memiliki pengetahuan kurang tentang praktik menyusui, sementara itu pola kebiasaan 
yang ada di masyarakat berkaitan dengan praktik menyusui, mungkin masih banyak yang belum melakukan praktik menyusui yang benar. Kondisi ini akan memberi dorongan pada ibu menyusui untuk melakukan praktik menyusui seperti apa yang dilihatnya, sekalipun cara menyusui tersebut tidak menunjukkan praktik menyusui yang benar.

Ketidakmampuan ibu dalam melakukan praktik menyusui yang benar ini, bukan hanya berakibat pada kemungkinan kurang berhasilnya ibu memberikan ASI pada bayinya, tetapi juga berakibat pada kesehatan bayi itu sendiri, seperti diare ataupun kurang tepenuhinya kebutuhan nutrisi bayi yang dibutuhkan dari ASI ibunya. Apabila ibu tidak mampu melakukan praktik menyusui yang benar, kemungkinan pemberian ASI secara ekslusif bagi bayinya juga kemungkinan sulit dilakukan, karena ibu tidak memiliki pengetahuan dan pemahaman yang baik tentang menyusui pada bayinya..

\section{Hubungan Kualitas ANC dengan Praktik menyusui yang benar}

Ante natal care merupakan wahana bagi setiap bidan untuk memberikan pelayanan yang dibutuhkan oleh setiap ibu hamil, salah satunya pengetahuan tengan menysui bayinya setelah lahir. Pelayanan seperti ini merupakan salah satu kegiatan yang harus dilakukan bidan, terutama saat memberikan layanan konseling pada waktu ibu melakukan ante natal care. Dalam praktiknya, masih banyak ibu - ibu hamil yang belum melakukan ante natal care dengan baik selama hamilnya, sehingga pengetahuan maupun pemantauan kesehatan ibu maupun bayinya belum dapat dilakukan dengan baik. Gambaran ini sebagai mana terlihat pada hasil penelitian, yang menunjukan bahwa responden yang melakukan praktik menyusui kurang baik proporsinya lebih tinggai pada ibu dengan kualitas ANC yang tidak baik $(80,4 \%)$ dibanding ibu dengan kualitas ANC yang baik ( $46 \%$ ).

Gambaran ini menunjukan bahwa betapa pentingnya ibu hamil melakukan ante natal care dengan baik, karena melalui pelayanan ante natal care yang baik ini ibu akan memperoleh pengetahuan dan pemahaman tentang kesehatannya maupun bayinya termasuk tentang bagaimana cara menyusui yang benar saat bayinya telah lahir. Perlunya ibu melakukan ante natal care yang baik ini, sesuai dengan gambaran hasil penelitian yang didapat, bahwa berdasarkan hasil uji statistic kai skuer pada alpha 0,05 diperoleh nilai $\mathrm{p}=0,00(\mathrm{P}<0,05)$, yang 
berarti bahwa secara statistic ada hubungan antara kualitas ANC dengan praktik menyusui yang benar. Hasil analisis lebih lanjut diperoleh nilai prevalen ratio sebesar 5,177 yang berarti bahwa ibu dengan kualitas ANC yang tidak baik memiliki peluang untuk melakukan praktik menyusui yang kurang baik 5,177 kali dibanding ibu dengan kualitas ANC yang baik.

\section{Hubungan Paritas dengan Praktik} Menyusui yang benar

Dalam melakukan praktik menyusui yang benar, selain membutuhkan pengetahuan yang baik tentang menyusui bayi, juga diperlukan pengalaman dalam memberikan ASI pada bayinya. Tidak sedikit ibu - ibu muda yang beru pertama kali memberikan ASI pada bayinya mengalami kesulitan dalam melakukan praktik menyusi yang benar pada bayinya. Upaya mempersiapkan diri untuk mampu memberikan ASI pada bayinya, mungkin telah dilakukannya sejak usia kehamilannya, namun pengalaman baru menjadi seorang ibu kadang mempengaruhi terhadap keberhasilannya dalam memberikan ASI pada bayinya. Keadaan seperti ini sejalan dengan hasil penelitian yang penulis lakukan yang menunjukan bahwa responden yang melakukan praktik menyusui kurang baik proporsinya lebih tinggi pada ibu dengan primipara $(70 \%)$ dibanding ibu dengan Multipara ( 43,7\% ). Gambaran hasil ini memperkuat keyakinan kita akan perlunya pengalaman dalam memberikan ASI pada bayinya. Pada ibu menyusui dengan multipara, pengalaman telah diperolehnya pada saat memberikan ASI pada anak sebelumnya, sehingga pada kelahiran anak saat penelitian dilakukan, mereka telah memiliki kemampuan dalam memberikan ASI yang baik pada bayinya. Faktor paritas yang memiliki pengaruh pada kemampuan melakukan praktik menyusui yang benar ini juga sejalan dengan yang dihasilkan peneliti pada analisis hubungan statistic yang menunjukan adanya hubungan antara paritas dengan praktik menyusui yang benar. Hasil analisis lebih lanjut diperoleh nilai $\mathrm{OR}=1,7$ yang berarti bahwa ibu dengan prmipara memiliki peluang untuk melakukan praktik menyusui yang kurang baik 1,43 kali dibanding ibu dengan multipara

\section{Hubungan Pendidikan ibu dengan praktik menyusui yang benar}

Pendidikan merupakan salah satu factor yang berpengaruh terhadap pengetahuan seseorang. Secara umum seoarang yang memiliki tingkat pendidikan yang tinggi 
akan memiliki pengetahuan yang tinggi pula. Dalam realitasnya memang tidak selalu sesoarng yang berpendidikan tinggi akan memiliki prilaku yang baik seperti yag diketahuinya, oleh karena pendidikan tidak selalu berhubungan erat dengan perilaku baik seseorang. Gambaran ini sejalan dengan yang penulis dapatkan pada hasil penelitian yang menunjukan bahwa responden yang melakukan praktik menyusui kurang baik proporsinya sedikit lebih tinggi pada ibu dengan pendidikan rendah (59,2 \%) dibanding ibu dengan pendidikan tinggi ( $51,4 \%$ ).

Hasil penelitian ini sejalan dengan yang ditemukan Siswanto (2007) pada penelitian tentang pola,trend dan perbedaan praktik menyusui, bahwa praktik menyusui pada wanita yang berpendidikan tinggi cenderung memiliki praktik menyusui yang lebih singkat dibanding wanita yang berpendidikan rendah. Pendidikan yang tinggi pada wanita, biasanya berkaitan dengan pekerjaan wanita tersebut. Wanita yang berpendidikan tinggi umumnya memiliki pekerjaan di luar rumah, sehingga hal ini seringkali menjadi alasan wanita untuk melakukan praktik menyusui lebih singkat disbanding wanita yang bekerja di dumah.

Jurnal Medikes, Volume I, edisi I, April 2014
Hasil uji statistic kai skuer pada alpha 0,05 diperoleh nilai $\mathrm{p}=0,37(\mathrm{P}>0,05)$, yang berarti bahwa secara statistic tidak ada hubungan antara pendidikan dengan praktik menyusui yang benar. Perbedaan yang relative sedikit ini menunjukan bahwa pendidikan seseorang tidak selalu berhubungan dengan perilaku yang baik seperti pengetahuan yang dimilikinya. Sementara itu praktik menyusui bagi seorang wanita merupakan salah satu prilaku instinktif yang dimiliki wanita yang telah memiliki bayi, selain itu proses transformasi pengalaman yang turun temurun dari keluarganya, juga mendukung dalam meningkatkan kemampuan ibu dalam memberikan air susu pada bayinya

\section{Hubungan pengetahuan ibu dengan praktik menyusui yang benar}

Pengetahuan merupakan factor yang penting dalam melakukan sesuatu. Kemampuan seorang ibu untuk melakukan perawatan dan pemeliharan bayi yang baik bergantung pada kemampuan pengetahuan dan pengalaman yang dimilikinya. Hasil penelitian menunjukan bahwa responden yang melakukan praktik menyusui kurang baik proporsinya lebih tinggai pada ibu dengan pengetahuan kurang praktik menyusui $(75,9 \%)$ dibanding ibu dengan pengetahuan yang baik ( $38,8 \%)$. 
Keadaan ini menggambarkan bahwa ibu yang memiliki pengetahuan kurang, akan mengalami kesulitan bahkan tidak mampu untuk melakukan praktik menyusui yang benar pada bayinya. L. Green menjelaskan bahwa pengetahuan merupakan factor predisposing untuk terbentuknya perilaku, oleh karena factor pengetahuan menjadi hal penting dalam merubah perilaku seseorang. Perilaku praktik menyusui yang tidak benar, akan dapat diubah apabila ibu diberikan informasi yang baik tentang praktik menyusui pada bayinya. Informasi tentang hal ini dapat dilakukan saat ibu melakukan ante natal care pada bidan. Melalui proses tranformasi pengetahuan seperti ini diharapkan akan terbangun siklus kecerdasan pada ibu khususnya dalam hal praktik menyusui yang benar.

Gambaran ini sesuai dengan hasil penelitian yang penulis lakukan yang menunjukan secara statistic ada hubungan antara kualitas ANC dengan praktik menyusui yang benar. Hasil analisis lebih lanjut diperoleh nilai OR = 1,9 yang berarti bahwa ibu dengan pengetahuan kurang tentang praktik menyuusi memiliki peluang untuk melakukan praktik menyusui yang kurang baik 1,9 kali dibanding ibu dengan kualitas ANC yang baik.

\section{Simpulan}

1. lebih dari setengahnya ( $55,9 \%$ ) responden kurang baik dalam melakukan praktik menyusui.

2. Variabel Kualitas ante natal care, paritas dan pengetahuan ibu tentang menyusi berhubungan dengan praktik menyusui yang benar, sementara itu variable pendidikan ibu tidak berhubungan denganpraktik menyusui yang benar.

\section{Saran}

Perlunya petugas kesehatan untuk selalu memberikan penyuluhan tentang praktik menyusui yang benar pada setiap ibu hamil yang melakukan layanan ante natal maupun upaya promosi lainya melalui leaflet atau brosur yang dapat dipelajari ibu hamil, sehingga pengetahuan ibu hamil tentang praktik menyusui yang benar akan meningkat. Peningkatan dan pemahaman yang baik tentang praktik menyusui pada ibu hamil akan mendorong terbentuknya prilaku yang baik bagi ibu dalam memberikan air susu bagi bayinya saat menyusui 


\section{Daftar Pustaka}

Arikunto, S. 2006. Prosedur Penelitian

Satu Pendekatan Praktek, Edisi V. Jakarta : Rineka Cipta.

Badan Pusat Statistik. 2008. Survei Demografidan Kesehatan Indonesia (SDKI) 2007

Budiarto, Eko. 2003. Metodologi Penelitian Kedokteran. Jakarta : EGC. Chandra, Budiman. 2008. Metodologi Penelitian Kesehatan. Jakarta : EGC.

Huliana, Mellyana. 2003. Perawatan Ibu Pasca Melahirkan. Jakarta : Puspa Swara.

Kumala, Poppy. 1998. Kamus Saku Kedokteran Dorland Edisi 25. Jakarta : EGC.

Notoatmodjo, Soekidjo. 2010. Metodologi Penelitian Kesehatan. Jakarta : Rineka cipta

Soetjiningsih, 1997, ASI Petunjuk Untuk Tenaga Kesehatan, Jakarta ; EGC Siswanto, AW, 2009, Jurnal Gizi Klinik Indonesia, Vol.6 No.1, 2009 
